\title{
TEKNIK MASSAGE EFFLURAGE DAPAT MENGURANGI NYERI KALA I PADA IBU BERSALIN DI PUSKESMAS HALMAHERA KOTA SEMARANG
}

\author{
Sri Rahayu \\ Akademi Kebidanan Abdi Husada Semarang, Indonesia \\ Jl.Kol.HR. Hadianto No. 70 Banaran Gunungpati, Semarang, Indonesia \\ virakina@gmail.com \\ Tanggal Submisi: 22 Februari 2020; Tanggal Penerimaan: 25 Mei 2020
}

\begin{abstract}
ABSTRAK
Pada tahun 2018 didapatkan data di Kota Semarang jumlah persalinan 25.150 perkelahiran hidup, dan pada bulan Januari - Agustus 2019 jumlah persalinan di puskesmas Halmahera berjumlah 234 orang. Salah satu pelayanan selama persalinan adalah pengurangan nyeri kala I dengan Massage Efflurage. Tujuan penelitian untuk mengetahui manfaat teknik massage Efflurage terhadap pengurangan nyeri kala I pada ibu bersalin di puskesmas Halmahera Tahun 2019. Jenis penelitian survey dengan desain penelitian metode pre-eksperimen dengan pendekatannya onegroup pra-post test design. Sampelnya ibu bersalin di puskesmas Halmahera pada bulan September November 2019 berjumlah 68 orang secara Accidental Sampling. Analisisnya uji Normalitas Saphiro-Wilk dan uji Wilcoxon didapatkan hasil sebelum massage efflurage responden mengalami nyeri sedang setelah massage efflurage menjadi nyeri ringan berjumlah 55 (80,9\%), sebelum massage efflurage responden mengalami nyeri berat setelah massage efflurage menjadi nyeri ringan berjumlah $4(5,9 \%)$ dan sebelum massage efflurage responden mengalami nyeri berat setelah massage efflurage menjadi nyeri sedang berjumlah 9 (13,2\%). Jadi pada Uji Wilcoxon teknik massage efflurage sangat bermanfaat terhadap pengurangan nyeri kala I ibu bersalin di puskesmas Halmahera Tahun 2019 dengan $\mathrm{p}=0.00$. Sarannya pada asuhan kebidanan dengan manajemen nyeri pada persalinan dengan massage efflurage dapat dijadikan suatu intervensi dalam manajemen sensasi nyeri persalinan pada asuhan sayang ibu.
\end{abstract}

Kata Kunci : Ibu bersalin, Massage efflurage, Nyeri

ISSN 1979-7621 (Print). ISSN 2620-7761 (Online).

\begin{abstract}
In 2018 the data obtained in the city of Semarang number of 25,150 births per live birth, and in January - August 2019 the number of deliveries at the Puskesmas Halmahera totaled 234 people. One of the services during labor was reducing the pain of the first stage with massage efflurage. The purpose of this study was to determine the benefits of the Efflurage massage technique on the reduction of pain in the first stage of maternity at the Halmahera Health Center in 2019. The type of survey research was the pre-experimental method research design with the onegroup pre-post test design approach. The sample of women giving birth at the Halmahera Public Health Center in September - November 2019 amounted to 68 people by accidental sampling.
\end{abstract}


The analysis of Saphiro-Wilk normality test and Wilcoxon test results showed that before massage efflurage respondents experienced moderate pain after massage efflurage to mild pain totaling 55 (80.9\%), before massage efflurage respondents experienced severe pain after massage efflurage to mild pain totaling $4(5.9 \%)$ and before massage efflurage, respondents experienced severe pain after massage efflurage to moderate pain, amounting to $9(13.2 \%)$. The Wilcoxon Test efflurage massage technique was very useful for the reduction of the first stage pain in maternity mother in the Halmahera Health Center in 2019 with $p=0.00$. The advices on midwifery care with pain management in labor with massage efflurage can be used as an intervention in the management of labor pain sensations in care for maternal affection.

Keywords: Massage efflurage, Maternity, Pain

\section{PENDAHULUAN}

Pada tahun 2030 World Health Organization (WHO) menargetkan rasio kematian ibu secara global menjadi kurang dari 70 per 100.000 kelahiran hidup, tahun 2015 sekitar 830 wanita meninggal setiap hari karena komplikasi kehamilan atau melahirkan dengan rasio kematian ibu dari 216 per 100.000 kelahiran hidup (WHO, 2017).

Angka Kematian Ibu (AKI) atau maternal di Indonesia yang merupakan indikator keberhasilan upaya kesehatan ibu, di antaranya dapat dilihat dari indikator AKI selama masa kehamilan, persalinan dan nifas yang disebabkan oleh kehamilan, persalinan, dan nifas. Penurunan AKI di Indonesia terjadi sejak tahun 2010 sebanyak 214 per 100.000 kelahiran hidup, tahun 2012 menunjukkan peningkatan AKI yang signifikan yaitu menjadi 359 kematian ibu per 100.000 kelahiran hidup. Tahun 2015 AKI menjadi 305 kematian ibu per 100.000 kelahiran hidup berdasarkan hasil Survei Penduduk Antar Sensus (SUPAS) (Kemenkes RI, 2017).

Data profil Kesehatan Provinsi Jawa Tengah tiga tahun ke belakang pada tahun 2015 jumlah Angka Kematian Ibu (AKI) sebanyak 619 kasus atau 111,16 per 100.000 kelahiran hidup, tahun 2016 sebanyak 602 kasus dari 109,65 per 100.000 kelahiran hidup, dan 2017 (Triwulan III) sebanyak 337 kasus atau 66,145 per 100.000 kelahiran hidup dan tahun 2018 sebanyak 421 kasus sehingga dapat di simpulkan bahwa dari tahun 2015 sampai 2018 AKI mengalami penurunan (Dinkes Provinsi Jawa Tengah, 2017).

Jumlah persalinan dengan pertolongan tenaga kesehatan di Kota Semarang pada tahun 2016 adalah 26.444 (100\%) dari 24.666 persalinan. Angka ini sudah melampaui target SPM tahun 2016 (95\%). Upaya yang telah dilakukan oleh Dinas Kesehatan Kota Semarang untuk menurunkan AKI dan AKB yaitu dengan meningkatkan kunjungan ibu hamil. Cakupan pelayanan antenatal ibu hamil dapat dipantau melalui pelayanan kunjungan baru ibu hamil K1 untuk melihat akses dan pelayanan kesehatan ibu hamil sesuai standart, yaitu paling sedikit 4 kali (K4) dengan distribusi 1 kali pada triwulan petama, 1 kali pada triwulan kedua dan 2 kali pada triwulan ketiga (Dinkes Kota Semarang, 2018).

$$
\text { Pada bulan September }
$$

November 2019 di Puskesmas Halmahera kota Semarang jumlah persalinan normal terdapat 68 ibu melahirkan, Hasil survey awal terhadap $10 \mathrm{ibu}$ bersalin di puskesmas Halmahera pada bulan Agustus 2019 menyatakan merasakan nyeri persalinan pada kala I dan belum 
pernah dilakukan pengukuran rasa nyeri oleh bidan, belum pernah dilakukan penelitian tentang kegunaan perlakuan pijat effleurage tetapi bidan sudah memberikan perlakuan pijat punggung (Puskesmas Halmahera Semarang, 2018).

Penelitian ini dirumuskan bahwa apakah nyeri persalinan terutama pada kala I dapat dicegah dengan menggunakan teknik pijat effleurage.. Nyeri harus diringankan dengan efektif karena bila nyeri disertai reaksi stress memiliki dampak berbahaya bagi ibu dan janin, nyeri persalinan merupakan suatu kondisi yang fisiologis (Handayani, 2016). Persalinan adalah proses pengeluaran hasil konsepsi yang telah cukup bulan atau dapat hidup diluar kandungan melalui jalan lahir atau melalui jalan lain (Manuaba, 2010).

Nyeri persalinan merupakan perasaan tidak menyenangkan yang terjadi selama proses persalinan. Secara fisiologi nyeri persalinan mulai timbul pada persalinan kala I fase laten dan fase aktif. Pada fase aktif terjadi pembukaan mulai 3-10 cm. Nyeri disebabkan karena kontraksi uterus dan dilatasi serviks. Makin lama nyeri dirasakan akan bertambah kuat. Puncak nyeri terjadi pada fase aktif dimana pembukaan lengkap sampai $10 \mathrm{~cm}$, intensitas nyeri tersebut mempengaruhi kondisi psikologis ibu, proses persalinan dan janin (Potter dan Perry, 2006).

Nyeri pada saat persalinan mulai timbul pada kala I fase laten dan fase aktif. Pada fase laten, nyeri dirasa kuat dan teratur namun berlangsung lama, pembukaan serviks berlangsung selama 8 jam pada fase ini, seiring bertambahnya frekuensi dan intensitas kontraksi uterus, nyeri yang dirasakan semakin bertambah kuat dan memuncak pada fase aktif, dimana pada fase ini pembukaan lengkap berlangsung sekitar 4,6 jam bagi primipara dan 2,5 jam bagi multipara (Fitriyanti, 2017).
Penelitian ini mempunyai manfaat yaitu rasa nyeri pada ibu bersalin kala I dapat berkurang dengan teknik pijat effleurage artinya menekan dengan lembut memijat dengan tangan untuk melancarkan peredaran darah. Dengan tehnik memijat dan tenang berirama, bertekanan lembut kearah distal atau kearah bawah, suatu rangsangan pada kulit abdomen dengan menggunakan usapan menggunakan ujung-ujung jari telapak tangan dengan arah gerakan membentuk pola gerakan seperti kupukupu abdomen sering dengan pernapasan abdomen. Hal ini dapat menurunkan kotraksi uterus, penurunan sirkulasi uteroplasenta, pengurangan aliran darah dan oksigen ke uterus, serta menimbulkan iskemik uterus yang membuat impuls nyeri bertambah banyak sehingga nyeri persalinan dapat berkurang.Maka Dinas Kesehatan Kota Semarang dalam mengambil kebijakan akan menjadikan teknik pijat effleurage sebagai acuan dan panduan dalam mengurangi rasa nyeri pada ibu bersalin kala I. Adapun tujuan penelitian ini adalah mengevaluasi pengurangan nyeri pada kala I ibu bersalin setelah mendapatkan massage effleurage di Puskesmas Halmahera kota Semarang.

\section{METODE PENELITIAN}

Jenis penelitian yang digunakan adalah penelitian pre-eksperimen dengan pendekatannya onegroup pre-post test design. Penelitian ini telah dilaksanakan di Puskesmas Halmahera pada tanggal 5 September sampai dengan 12 November 2019 dengan meminta persetujuan responden menggunakan inform consent.

Populasi dalam penelitian ini adalah semua ibu Hamil yang bersalin pada waktu penelitian di Puskesmas Halmahera berjumlah 68 orang. Dengan jumlah sampel dalam penelitian sebanyak 68 orang ibu bersalin dengan teknik 
pengambilan sampel yaitu accidental sampling. Pada waktu pengambilan data dilakukan pada ibu bersalin sebelum merasa nyeri dan sudah merasa nyeri dengan melakukan massage effluerence yang dilakukan oleh tenaga bidan terlatih pada setiap ibu bersalin kala I yang datang di puskesmas Halmahera kemudian ibu bersalin diwawancara untuk mengisi kuesioner, dibutuhkan sampai ibu bersalin masuk kala II dan untuk mengukur nyeri dengan mengisi wawancara menggunakan skala Numerical Rating Scales (NRS).

Waktu dilakukan penelitian di bulan September sampai bulan November 2019 dengan lembar observasi terdiri dari identitas responden yaitu umur, pendidikan, paritas dan observasi skala nyeri numerik 0-10 dengan penilaian:1 tidak ada nyeri (skala 0), 2:nyeri ringan (skala 1-3), 3:nyeri sedang (skala 4-6), 4:nyeri berat (skala 7-9), 5:nyeri sangat berat (skala 10).

Analisis dalam penelitian ini menggunakan uji normalitas data menggunakan Kolmogorof-Smirnov dan uji Wilcoxon, analisis menggunakan program computer Statistical Package for the Social Sciences (SPSS). Sebelum dilakukan analisis bivariat, terlebih dahulu dilakukan uji normalitas terhadap data yang telah diperoleh..

\section{HASIL DAN PEMBAHASAN}

\section{Karakteristik Responden}

Berdasarkan tabel 1 dapat diketahui sebagian besar responden dalam penelitian berusia 20-25 tahun sebanyak 56 orang $(82,4 \%)$, sedangkan yang lebih 25 tahun ada 12 orang $(17,6 \%)$ yang mayoritas pada ibu bersalin dengan primipara 39 orang $(57,4 \%)$, dengan klasifikasi pendidikan SMA 31 orang $(45,6 \%)$.
Tabel 1

Distribusi Frekfensi Karasteristik Responden

\begin{tabular}{ccc}
\hline \multicolumn{1}{c}{ Variable } & $\begin{array}{c}\text { Frekwensi } \\
(\text { n })\end{array}$ & $\%$ \\
\hline Umur & 56 & 82,4 \\
$20-25$ tahun & 12 & 17,6 \\
$\quad 25$ tahun & 68 & 100 \\
Total & & \\
Pendidikan & 2 & 2,9 \\
SD & 29 & 42,6 \\
SMP & 31 & 45,6 \\
SMA & 6 & 8,8 \\
PT & 68 & \\
Total & & 57,4 \\
Paritas & 39 & 42,6 \\
Primipara & 29 & 100 \\
Multipara & 68 & \\
Total & & \\
\end{tabular}

\section{Nyeri Kala I Persalinan Sebelum Massage Efflurage}

Pada data nyeri kala I sebelum dilakukan massage efflurege pada responden di puskesmas Halmahera terdapat nyeri sedang berjumlah 55 responden $(80,9 \%)$ dan nyeri berat terdapat pada 13 responden $(19,1 \%)$ dikarenakan pelaksanaan massage efflurage pada ibu nifas di Puskesmas Halmahera Semarang terjadi nyeri kala I mayoritas pada kategori sedang karena ibu mengalami gejala terasa keram pada perut bagian bawah, nyeri menyebar ke pinggang, kurang nafsu makan, aktifitas terganggu, sedangkan sebagian yang kategori berat karena terasa keram berat pada perut bagian bawah, nyeri menyebar ke pinggang, paha, punggung, tidak ada nafsu makan, mual, badan lemas, tidak kuat beraktifitas. Sesuai pada penelitian Handayani (2016), diperoleh bahwa sebelum dilakukan massage efflurage lebih banyak responden yang mengalami nyeri sedang sebesar $53,6 \%$ dan berat sebesar 39,3\%.

Penelitian Fatmawati (2017), diperoleh sebelum masase efflurage nyeri sedang 62,5\%. Penelitian Paramita (2013), juga diperoleh skala nyeri sebelum dilakukan pijat effleurage 
terbanyak adalah menderita, yaitu sebanyak $60 \%$. Banyak faktor yang mempengaruhi nyeri persalinan, baik faktor internal maupun eksternal yang meliputi paritas, umur, budaya, mekanisme koping, emosional, tingkat pendidikan, lingkungan, kelelahan, kecemasan, lama persalinan, pengalaman masa lalu, support system dan tindakan medik (Magfuroh, 2012).

Nyeri yang dirasakan dipengaruhi oleh beberapa faktor seperti kecemasan dan ketakutan, pengalaman nyeri yang lalu, persiapan persalinan, sistem pendukung responden (Maryuyani, 2010). Berdasarkan teori tersebut maka nyeri harus diringankan dengan efektif karena bila nyeri disertai reaksi stress memliki efek atau dampak berbahaya bagi ibu dan janin, Nyeri persalinan merupakan suatu kondisi yang fisiologis, oleh sebab itu salah satu penanganan dalam penelitian ini yaitu dengan melakukan massage efflurage.

\section{Nyeri Kala I Sesudah Massage Efflurage}

Pada nyeri kala I sesudah dilakukan Massage Efflurage pada Responden di Puskesmas Halmahera menunjukkan bahwa dari 68 responden terbanyak nyeri kala I sesudah massage efflurage kategori ringan sebesar 59 responden $(86,8 \%)$, dan kategori sedang 9 responden $(13,2 \%)$. Setelah dilakukan massage efflurage pada ibu bersalin di Puskesmas Halmahera Semarang berhasil menurunkan nyeri kala I fase aktif. Diperoleh dari 55 ibu yang sebelumnya nyeri kala I kategori sedang menurun semua menjadi ringan karena hanya terasa keram pada perut bagian bawah, masih dapat ditahan, masih dapat melakukan aktifitas dan masih bisa konsentrasi. Selanjutnya 4 orang yang kategori nyeri berat menjadi ringan dan 9 orang yang kategori berat menjadi nyeri sedang. Sehingga didapatkan bahwa semua responden mengalami penurunan nyeri setelah dilakukan massage efflurage. Penurunan nyeri pada responden tersebut terjadi karena pemberian massage effleurage pada abdomen menstimulasi serabut taktil di kulit sehingga sinyal nyeri dapat dihambat. Stimulus dengan effleurage ini menghasilkan pesan yang dikirim lewat serabut A-beta, serabut yang menghantarkan nyeri cepat, yang mengakibatkan gerbang tertutup sehingga korteks serabri tidak menerima sinyal nyeri dan intensitas nyeri berubah/berkurang. Secara fisiologis teknik massage effleurage dapat menurunkan tingkat nyeri, hal ini sesuai dengan teori gate control yang menyatakan rangsangan-rangsangan nyeri dapat diatur atau dihalangi oleh pintu mekanisme sepanjang sistem pusat neurons (Guyton,2009).

Penelitian Handayani (2016) diperoleh bahwa sesudah dilakukan massage responden mengalami penurunan yaitu nyeri sedang sebesar $50 \%$ dan berat sebesar 42,9\%. Penelitian Fatmawati (2017), diperoleh setelah masase efflurage menjadi nyeri ringan 62,5\%. Penelitian Paramita (2013), juga diperoleh skala nyeri sesudah dilakukan pijat effleurage terbanyak adalah Nyeri ringan, yaitu sebanyak $60 \%$.

Teknik Massage Efflurage terhadap Pengurangan Nyeri Kala I pada Ibu Bersalin di Puskesmas Halmahera Semarang Tahun 2019

Hasil uji analisis untuk mengetahui kegunaan teknik massage efflurage terhadap pengurangan nyeri kala I pada ibu bersalin di Puskesmas Halmahera Semarang Tahun 2019 diuraikan pada Tabel 2. Berdasarkan tabel 2 ditunjukkan hasil penelitian ini bahwa pemberian massage effleurage yang dilakukan oleh peneliti sangat efektif terhadap nyeri persalinan kala I fase 
laten, hal ini terbukti dari hasil analisis data teknik massage efflurage efektif terhadap pengurangan nyeri kala I pada ibu bersalin di Puskesmas Halmahera Semarang Tahun 2019 dengan $\mathrm{p}=0,000$. yang sebelumnya pada hasil analisis data didapatkan nyeri kala I sebelum teknik massage efflurage pada ibu bersalin di Puskesmas Halmahera Semarang Tahun 2019 terbanyak kategori sedang sebesar 32 responden $(82,1 \%)$ dan kategori berat 7 responden $(17,9 \%)$.

Tabel 2.

Uji Hubungan Teknik Massage Efflurage terhadap Pengurangan Nyeri Kala I

\begin{tabular}{|c|c|c|c|c|c|c|c|c|}
\hline \multirow{3}{*}{$\begin{array}{c}\text { Nyeri Sebelum Massage } \\
\text { Efflurage }\end{array}$} & \multicolumn{4}{|c|}{$\begin{array}{c}\text { Skala Nyeri Sesudah } \\
\text { Massage Efflurage }\end{array}$} & \multirow{2}{*}{\multicolumn{2}{|c|}{ Jumlah }} & \multirow{2}{*}{\multicolumn{2}{|c|}{ Nilai }} \\
\hline & \multicolumn{2}{|c|}{ Ringan } & \multicolumn{2}{|c|}{ Sedang } & & & & \\
\hline & $\mathbf{n}$ & $\%$ & $\mathbf{n}$ & $\%$ & $\mathbf{n}$ & $\%$ & \multirow{4}{*}{$\begin{array}{l}\mathrm{p} \\
\alpha\end{array}$} & \multirow{4}{*}{$\begin{array}{l}=0,000 \\
=0,05\end{array}$} \\
\hline Sedang & 59 & 86,8 & 0 & 0 & 59 & 86,8 & & \\
\hline Berat & 3 & 3,1 & 6 & 9,4 & 9 & 12,5 & & \\
\hline Total & 62 & 89,9 & 6 & 9,4 & 68 & 100 & & \\
\hline
\end{tabular}

Pada nyeri kala I sesudah teknik massage efflurage pada ibu bersalin di Puskesmas Halmahera Semarang terbanyak kategori ringan sebesar 34 responden $(87,2 \%)$, dan kategori sedang 5 responden $(12,8 \%)$. Oleh karena itu, pemberian massage effleurage yang dilakukan suami dan teknik relaksasi nafas dalam dapat digunakan untuk intervensi pada saat mengalami nyeri persalinan. Sejalan dengan penelitian Wahyuningsih (2015), yang menyatakan bahwa ibu yang berkonsentrasi dalam menikmati perlakuan massage effleurage membuat ibu menjadi relaks dan tenang sehingga oksitosin akan membuat kontraksi menjadi adekuat. Semakin adekuat kontraksi rahim, semakin cepat pembukaan dan penipisan serviks.

Penurunan tingkat nyeri disebabkan ketika ibu inpartu yang merasakan nyeri setelah dilakukan massage efflurage, otak merespon melalui korteks serebri lalu dihantarkan ke hipotalamus, hipotalamus melepaskan Corticotrophin Releasing Factor (CRF) lalu merangsang kelenjar pituitary untuk memberitahu medulla adrenal dalam meningkatkan produksi prooploidmelanocortin (POMC) sehingga enkhepalin meningkat. Kelenjar pituitary menghasilkan hormone endorphin sebagai neurotransmitter yang dapat mempengaruhi suasana hati menjadi rileks. Peningkatan endhorphin dan enkhepalin menyebabkan tubuh menjadi rileks dan rasa nyeri berkurang (Guyton, 2009).

\section{KESIMPULAN}

Teknik massage efflurage dapat mengurangi ketegangan, meningkatkan relaksasi fisik dan emosional dengan mengurangi kecemasan dan dengan dibantu datangnya pasangan atau suami untuk dilakukannya tindakan massage effleurage, karena sebagian besar suami hadir dalam proses persalinan dan untuk mendukung apapun tindakan yang dilakukan oleh tenaga kesehatan kepada ibu inpartu. Maka dapat disimpulkan bahwa Teknik massage efflurage efektif terhadap pengurangan nyeri kala I fase aktif pada ibu bersalin di Puskesmas Halmahera Kota Semarang Tahun 2019 dengan $\mathrm{p}=0,000$.

\section{UCAPAN TERIMAKASIH}

Terimakasih kepada ibu bersalin Puskesmas Halmahera Semarang yang 
telah bersedia menjadi responden dan terimakasih kepada kepala Puskesmas Halmahera beserta staf karyawan yang telah membantu penelitian sehingga berlangsung dengan lancar.

\section{DAFTAR PUSTAKA}

Dinkes Provinsi Jateng. (2017). Profil Kesehatan ProvinsiJawa Tengah.

Dinkes Kota Semarang (Puskesmas Halmahera). (2018). Data Persalinan. Semarang.

Fatmawati, I. (2017). Efektivitas Senam Dismenore dan Teknik Effleurage Terhadap Penurunan Dismenore pada Remaja. Journals of Ners Communit. 9(2)

Fitriyanti. (2017). Efektivitas Massage Effleurage yang dilakukan Suami terhadap Nyeri Persalinan Kala I Fase Laten Di Kecamatan Setu

Guyton. (2009). Buku Ajar Fisiologi Kedokteran. Edisi 9. Jakarta : EGC

Handayani, S. (2016). Massage Effleurage Terhadap Tingkat Nyeri Kala 1 Fase Aktif, Jurnal Kesehatan Samodra Ilmu. 7(2)

Kemenkes RI. (2017). Profil Kesehatan Indonesia. Jakarta

Magfuroh, A. (2012). Faktor-Faktor yang Berhubungan dengan Nyeri Persalinan Kala I Fase Aktif di Ruang Bersalin Rumah Sakit Umum Kabupaten Tangerang. Fakultas kodekteran dan Ilmu Kesehatan Universitas Islam Negeri Syarif Hidayatullah, Jakarta

Manuaba, I.B.G. (2010). Ilmu kebidanan, Penyakit Kandungan dan Keluarga Berencana untuk Pendidikan Bidan. Jakarta: EGC

Maryunani. (2010). Nyeri Dalam Persalinan. Trans Info Media, Jakarta

Potter dan Perry. (2006). Buku Ajar Fundamental Keperawatan Volume 2. Jakarta: EGC

Paramita, I. (2013). Efektivitas Perlakuan Pijat Effleurage pada Kala I Fase Aktif Persalinan untuk Mengurangi Rasa Nyeri pada Ibu Bersalin di BPM Yusnaeni Bulan Mei Tahun 2013. ejurnal STIKes Guna Bangsa Yogyakarta

Wahyuningsih, M. (2015). Efektivitas Aromaterapi Lavender (Lavandula Angustifolia) dan Massage Effleurage terhadap Tingkat Nyeri Persalinan Kala I Fase Aktif Pada Primigravida Di BPS Utami dan Ruang Ponek RSUD Karanganyar. Program Studi S-1 Keperawatan Stikes Kusuma Husada

WHO. (2017). World Health Statistic 2017 Monitoring Health For The Sustainable Development Goals, Design and layout by L'IV Com Sàrl, Villars-sous-Yens, Switzerland. Printed in France. ISBN 978-92-4-156548-6. 